Case Report

\title{
Nephron Sparing Surgery for Renal Angiomyolipoma with Inferior Vena Cava Thrombus in Tuberous Sclerosis
}

\author{
Adrien Riviere, Thomas Bessede, and Jean-Jacques Patard \\ Hôpital Bicêtre, 78 Rue du Général Leclerc, 94275 Le Kremlin-Bicêtre, France \\ Correspondence should be addressed to Adrien Riviere; riviere.adrien@free.fr \\ Received 19 December 2013; Accepted 8 January 2014; Published 23 February 2014
}

Academic Editors: G. Carmignani, H. Ito, and F. Koga

Copyright (C) 2014 Adrien Riviere et al. This is an open access article distributed under the Creative Commons Attribution License, which permits unrestricted use, distribution, and reproduction in any medium, provided the original work is properly cited.

Introduction. Angiomyolipoma is a common benign renal tumor. It is associated with Tuberous Sclerosis Complex (TSC) in 20\% of patients. Angiomyolipomas are classically multiple, bilateral, and growing; they may lead to complications such as Wunderlich syndrome or, in rare cases, to venous extension. Observation. a 74-year-old woman with TSC presented with an angiomyolipoma of the right kidney with inferior vena cava (IVC) fatty thrombus. She underwent partial nephrectomy and thrombectomy. After a 7-year follow-up there was no evidence of recurrence or metastasis and her renal function was preserved. Review of Literature. It is the 44th reported angiomyolipoma associated with IVC thrombus. The mean size of angiomyolipomas was $86.1 \mathrm{~mm}$ and $67.4 \%$ of patients were symptomatic. Pulmonary embolism was found in 6 patients. There were 2 cases of recurrence/metastatic outcome after radical nephrectomy and thrombectomy. They were associated with epithelioid form. The mean size of epithelioid tumors was significantly bigger than in classical angiomyolipomas $(127.1 \mathrm{~mm}$ versus $82.6 \mathrm{~mm}, P=0.037)$. With a median follow-up of 12 months, $91.3 \%$ of patients were recurrence and metastasis free, with 3 cases of nephron sparing surgery. Conclusion. Nephron sparing surgery for angiomyolipoma with IVC fatty thrombus can be safely performed in TSC, even in sporadic angiomyolipoma.

\section{Introduction}

Angiomyolipomas (AMLs) represent $0.3 \%$ of all renal tumors. The sex ratio is 4 men for 11 women. Most of the time, AMLs are sporadic but in $20 \%$ of patients AMLs are associated with Tuberous Sclerosis Complex. Thus they are classically multiple, bilateral, and growing [1]. They may become symptomatic and may require active management which has to be as conservative as possible. Many cases of inferior vena cava thrombus associated with AML have been reported [2-43]. We report a new clinical case of AML with inferior vena cava thrombus in a TSC patient that raises the question of the best surgical approach regarding the necessity of preserving renal function.

\section{Materials and Methods}

2.1. Observation. A 74-year-old woman with tuberous sclerosis and multiple bilateral AML who had undergone partial polar superior nephrectomy for a renal cell carcinoma in 1990 came after 7 years of surveillance with the evidence of an inferior vena cava thrombus developed from the right renal vein (Figure 1).

Computerized tomography showed multiple renal tumors with spontaneous density inferior to-20 Hounsfield Units (HU) without contrast enhancement. One of these typical AML that was already present in the previous studies was in contact with a homogenous tumor thrombus, wellcircumscribed, with the same fatty density and was extended in the inferior vena cava from the right renal vein, below the hepatic veins (Figure 2). Serum creatinine was $63 \mu \mathrm{mol} / \mathrm{L}$.

Partial nephrectomy without arterial clamping, lymphadenectomy, or adrenalectomy with thrombectomy was performed. The thrombus was free from the wall of the inferior vena cava and without fibrin clot. The postoperative period revealed to be uneventful. Serum creatinine was $98 \mu \mathrm{mol} / \mathrm{L}$, on postoperative day 7 when patient was discharged.

Pathologic examination showed a 7-centimeter yellowish tumor, extended with a thrombus presenting the same aspect. 


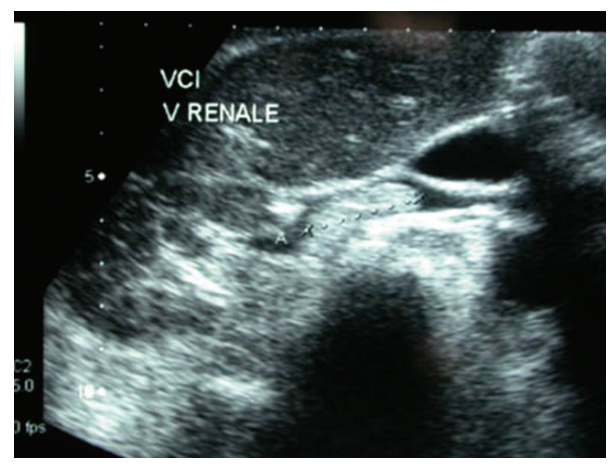

FIGURE 1: Sonography of the IVC thrombus originated from the right renal vein.

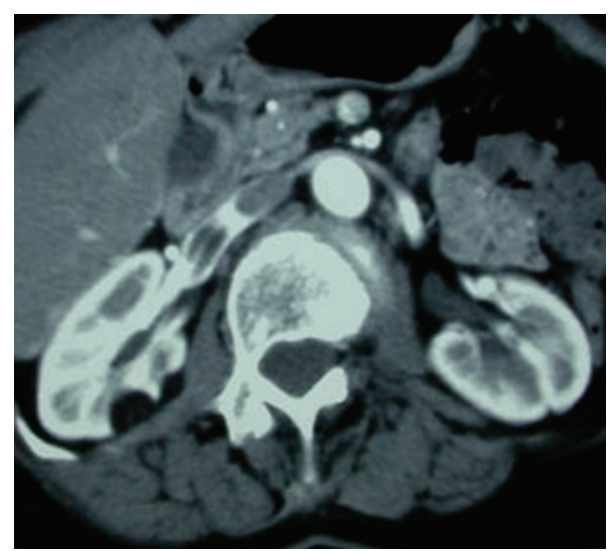

FIgURE 2: Axial contrast enhanced abdominal CT showing an IVC and renal thrombus with attenuation value $-70 \mathrm{HU}$.

It confirmed the diagnosis of AML given by the association of mature adipose tissue, thick-walled blood vessels, and smooth muscle cells. There was no epithelioid contingency.

Clinical and radiological surveillance after 11 years showed no signs of recurrence or metastasis. The renal vein and inferior vena cava were permeable and the renal function was preserved with $78 \mu \mathrm{mol} / \mathrm{L}$ serum creatinine.

2.2. Literature Review. A MEDLINE review was performed in order to identify all articles entirely published in English and evaluate inferior vena cava extension of AMLs.

All data are presented in Table 1.

\section{Discussion}

Venous extension of an AML is rare. We have identified 44 cases of inferior vena cava involvement in the literature including this one.

Medium age was 46.6 years (range $16-75$ years). It has a clear female predominance, representing $81.9 \%$ of patients. It is concordant to what is observed for common AML [1].

AMLs were bilateral in $31.9 \%$ of patients but were associated with TSC only in $11.4 \%$ of them.

Surprisingly, we found one case, reported by Camúñez et al. [5] with AML and IVC thrombus without right renal vein involvement. The patient had TSC and bilateral AML and did not undergo surgery. A similar case was reported by Ackali et al.; they described a right renal vein thrombus which extended in the IVC without any tumor of the right kidney on ultrasound examination, computer assisted tomography (CT), and even magnetic resonance imaging (MRI) [27]. They concluded that tumor might have originated from the kidney and then extended to the right renal vein and IVC.

Patients were symptomatic in $67.4 \%$ of cases; all were experiencing pain. Gross hematuria was present in $9.3 \%$ of patients. Other symptoms were nausea and/or vomiting in $9.1 \%$ and fever in $6.8 \%$. Five patients $(11.4 \%)$ presented a Wunderlich syndrome with acute flank pain and drop of blood pressure or hemoglobin with consistent diagnosis of retroperitoneal hemorrhage due to the rupture of the tumor. TSC was present only in one case of retroperitoneal hemorrhage.

We found that the level thrombus reached the diaphragm in 9 patients $(20.5 \%)$ and got to the right atrium in 6 patients (13.6\%).

In this review, almost all tumors were larger than $4 \mathrm{~cm}$ with a mean size of $86.1 \mathrm{~mm}$. Only 2 patients presented a small AML with vena cava thrombus; they had TSC. It has been reported that, in TSC, AMLs are more often symptomatic and have a more aggressive growth pattern [44].

As it has been previously reported, there is a large majority of right sided AML with inferior vena cava thrombus $(88.6 \%$ versus $11.4 \%)$. There is no clear explanation for it. According to Islam et al., when thrombus is limited to the renal vein there is no difference between left or right side [25]. In fact, we have to admit that, before extending into the inferior vena cava, the tumor thrombus was in the renal vein and therefore, predominantly, in the right one.

We also highlight the special case of AML with epithelioid cells which are now recognized as an individual tumor, different from classical AML $[45,46]$. In this review, recurrence or metastasis was only seen in patients with epithelioid contingency (2 patients, $8.7 \%$ ). Metastatic localization was the lungs for one and liver and peritoneum for the other. It appears that the size of the tumor is significantly bigger in AML with epithelioid contingency versus classical AML with mean size, respectively, of $127.1 \mathrm{~mm}$ versus $82.6 \mathrm{~mm}(P=$ $0.037, t$-test).

As reported by Park et al., all reported cases of metastasis of AML in literature were associated with the epithelioid form, expressing the melanocytic marker HMB-45 [28]. The only 2 documented patients with recurrence or metastasis were also epithelioid AML, in our review (HMB-45 positive).

This epithelioid form of AML, characterized by a minor amount of adipose tissues on imaging can mimic the appearance of a clear cell carcinoma [47]. It is reported to quickly evolve towards a metastatic situation with a lethal outcome because of its poor sensitivity to chemotherapy and targeted therapies [48]. Therefore it should be treated aggressively.

There are also malignant tumors presenting with evidence of fat on imaging. Hélénon et al. reported several fatcontaining renal cell carcinomas [49]. They were suggesting that diagnosis of AML should be reconsidered in presence of calcification, a large infiltrating or necrotic tumor with 


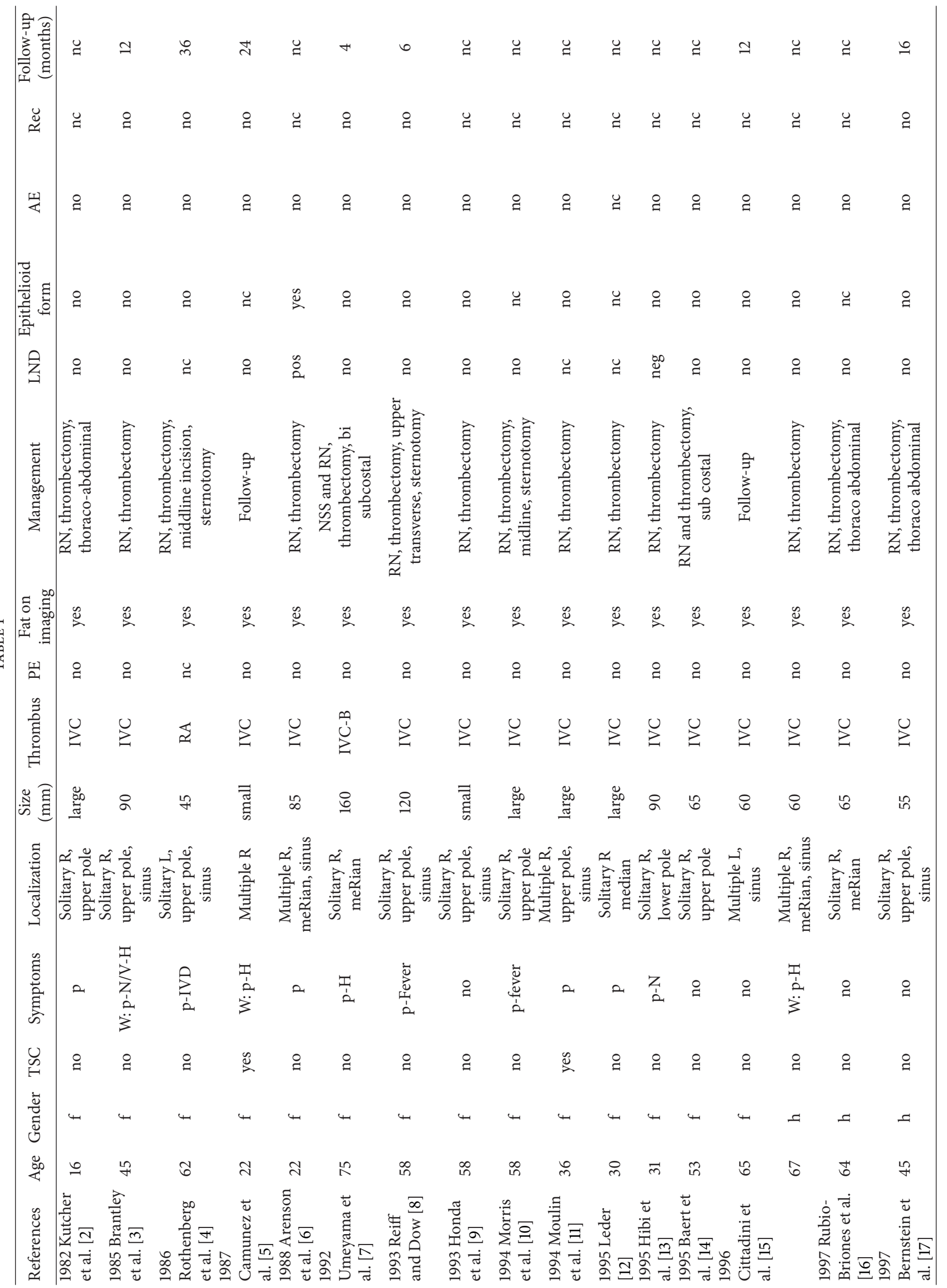




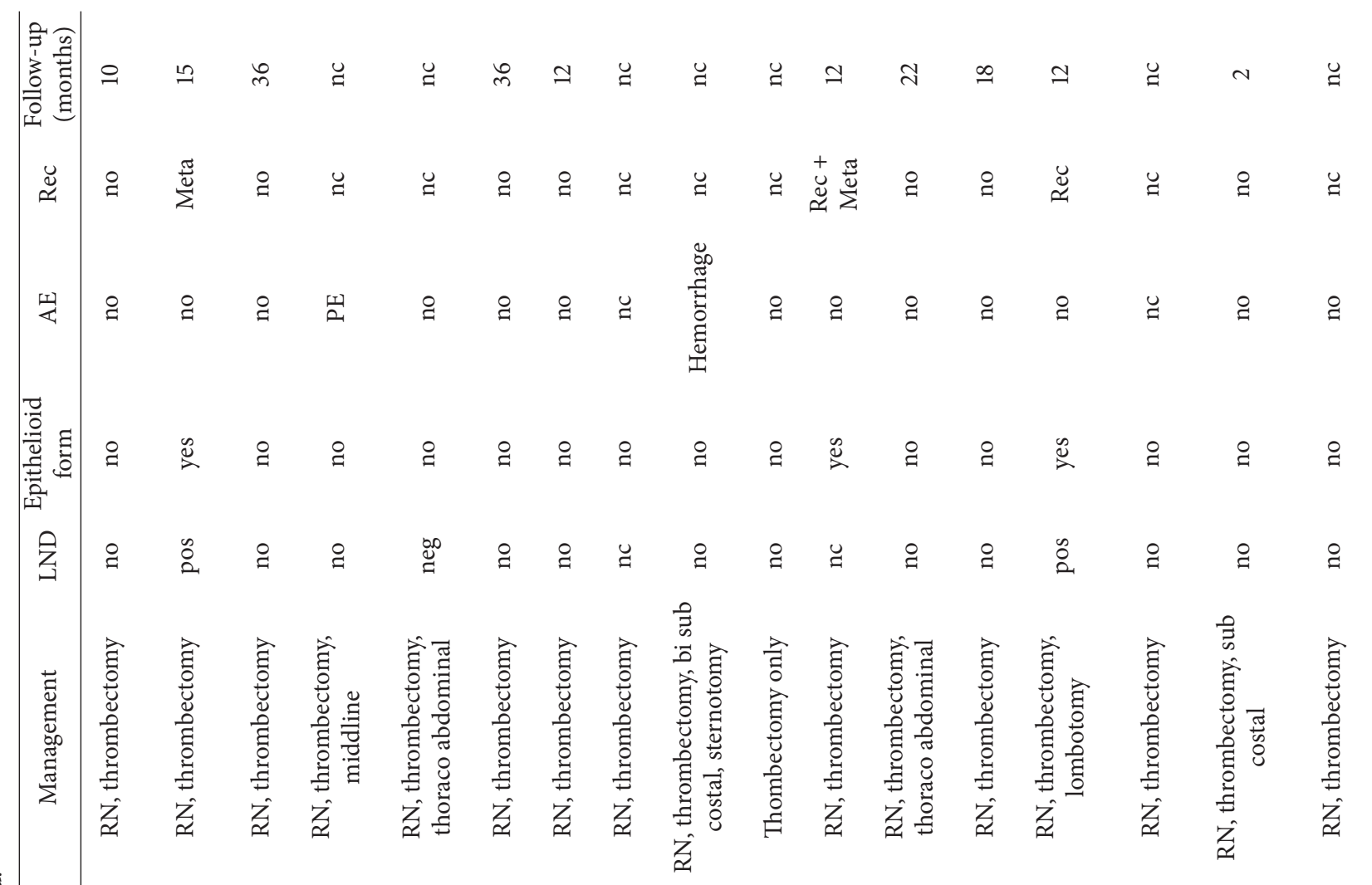

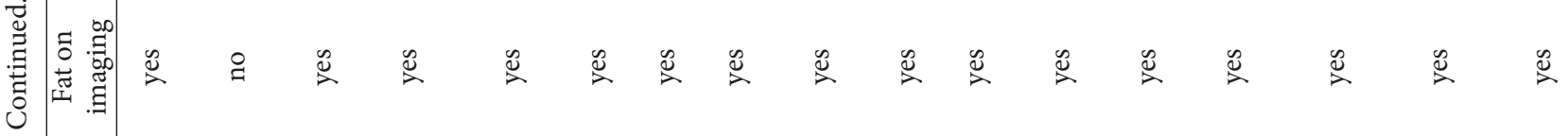

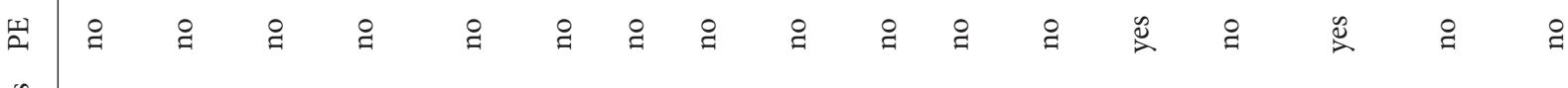

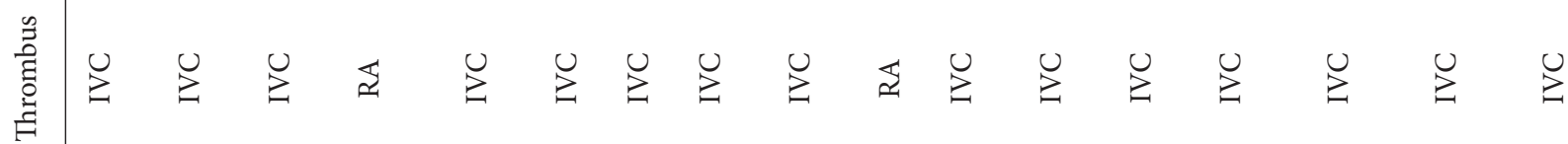

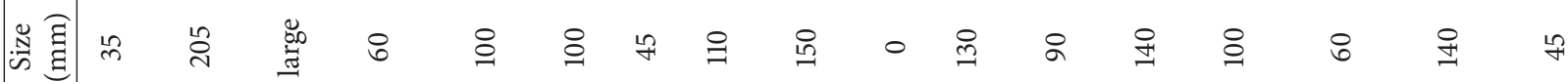

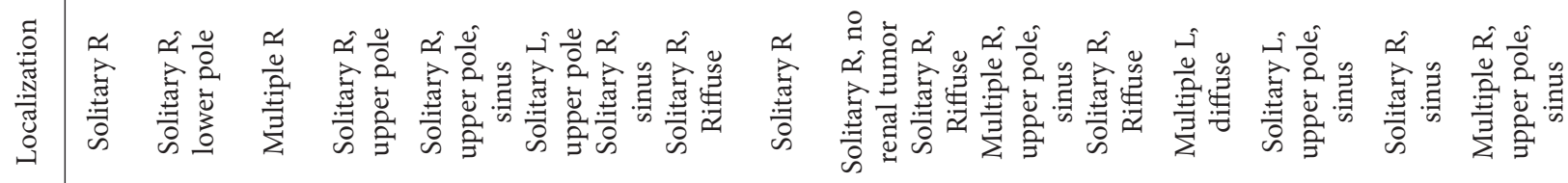

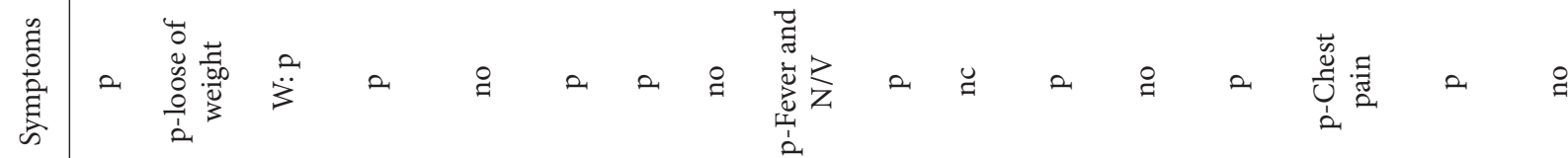

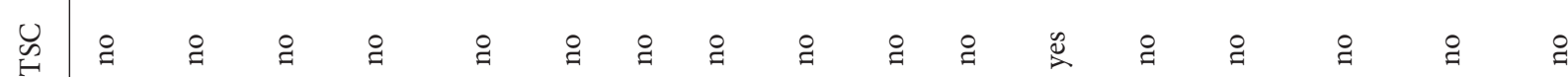

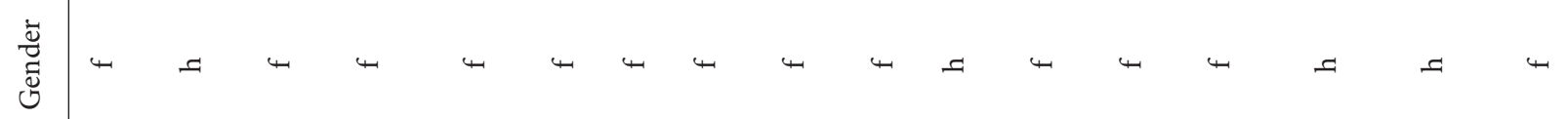

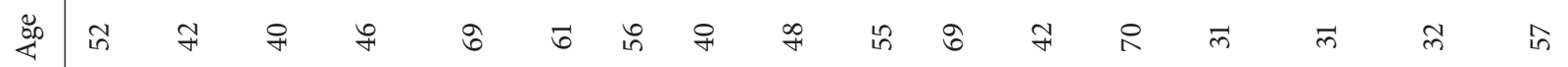

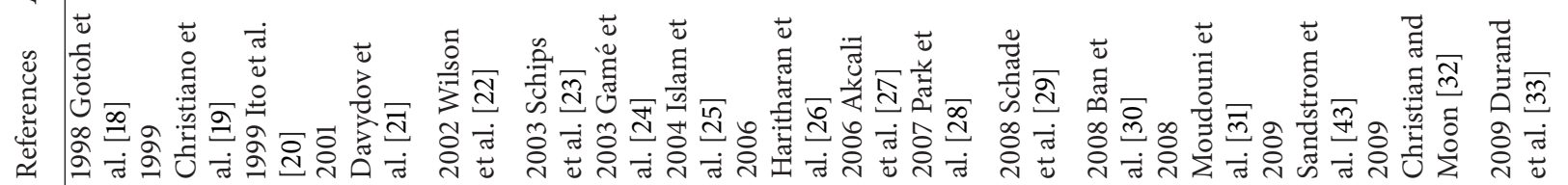




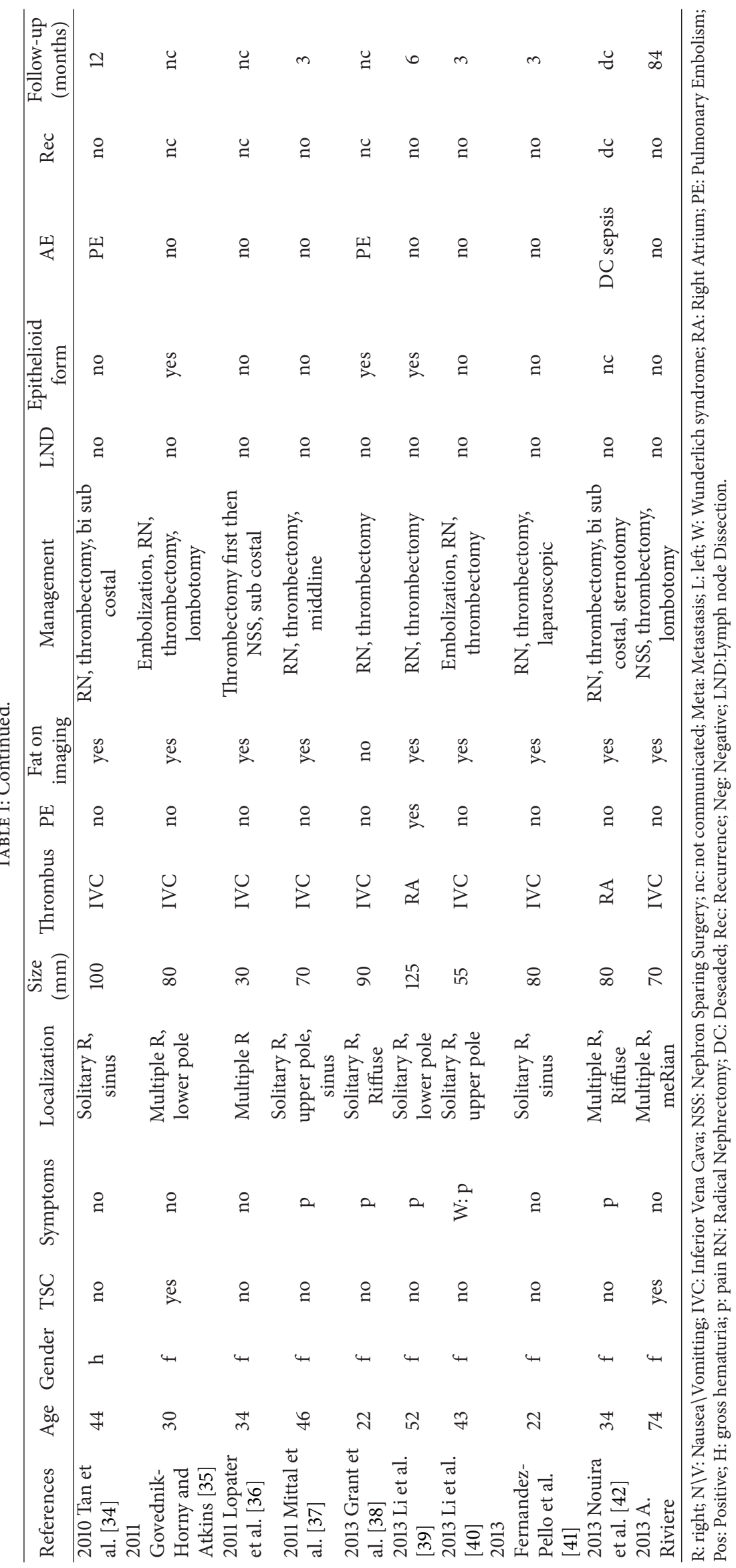


association of nonfatty lymph nodes or venous invasion. This review suggests that fat-containing tumors associated with venous fatty thrombus were not malignant tumors at risk of recurrence or metastasis.

In addition, classical AML can be wrongly perceived as clear cell carcinoma in case of recent hemorrhage or spindle cell predominance due to the almost undetectable fat component on imaging [50]. Those cases may benefit from fine-needle biopsy to rule out whether or not the conserving or radical approach should be taken.

Only symptomatic or larger-than-4-centimeter conventional AML should be considered for intervention. Many studies have correlated the risk of hemorrhage/symptomatic presentation with the size of the tumor $[51,52]$. In this review, mean tumor size was $86.1 \mathrm{~mm}$. Only several patients had medical history of AML and $11.4 \%$ of patients were known to have TSC. Those patients would have benefitted from surgical treatment.

A nephron sparing approach by either selective embolization or open or laparoscopic/robotic partial nephrectomy is recommended when an intervention is required [53-56].

In case of associated venous thrombus, the risk of expansion and cardiopulmonary embolism requires a surgical treatment. Case reported by Shinohara et al. presented with congestive heart failure with a thrombus extended to the right atrium [57].

In case of radical surgery, the prognosis is satisfying. 91.3\% of patients remained free from recurrence or metastasis at a median follow-up of 12 months (mean 16.8 months).

Although the presence of a venous thrombus suggests the malignant nature of the primary tumor, conservative surgery is possible. Cases of nephron sparing surgery for T3a or T3b renal cell carcinoma, whether for imperative indications (solitary kidney or renal failure) or intraoperative discovery of the thrombus, showed outcomes that seem acceptable compared to nonconserving surgery [58-60].

\section{Conclusion}

Nephron sparing surgery for AML with inferior vena cava extension in tuberous sclerosis is possible depending on the necessity of renal function preservation. It may be proposed as standard surgery for sporadic AML even with inferior vena cava thrombus.

\section{Conflict of Interests}

The authors declare that there is no conflict of interests regarding the publication of this paper.

\section{References}

[1] J. N. Eble, "Angiomyolipoma of kidney," Seminars in Diagnostic Pathology, vol. 15, no. 1, pp. 21-40, 1998.

[2] R. Kutcher, R. Rosenblatt, and S. M. Mitsudo, "Renal angiomyolipoma with sonographic demonstration of extension into the inferior vena cava," Radiology, vol. 143, no. 3, pp. 755-756, 1982.

[3] R. E. Brantley, J. W. Mashni, and R. E. Bethards, "Computerized tomographic demonstration of inferior vena caval tumor thrombus from renal angiomyolipoma," Journal of Urology, vol. 133 , no. 5, pp. 836-837, 1985.

[4] D. M. Rothenberg, T. D. Brandt, and I. D’Cruz, "Computed tomography of renal angiomyolipoma presenting as right atrial mass," Journal of Computer Assisted Tomography, vol. 10, no. 6, pp. 1054-1056, 1986.

[5] F. Camunez, J. Lafuente, R. Robledo et al., "CT demonstration of extension of renal angiomyolipoma into the inferior vena cava in a patient with tuberous sclerosis," Urologic Radiology, vol. 9, no. 3, pp. 152-154, 1987.

[6] A. M. Arenson, R. T. Graham, P. Shaw, J. Srigley, and S. Herschorn, "Angiomyolipoma of the kidney extending into the inferior vena cava: sonographic and CT findings," American Journal of Roentgenology, vol. 151, no. 6, pp. 1159-1161, 1988.

[7] T. Umeyama, Y. Saitoh, Y. Tomaru, and K. Kitaura, "Bilateral renal angiomyolipoma associated with bilateral renal vein and inferior vena caval thrombi," Journal of Urology, vol. 148, no. 6, pp. 1885-1887, 1992.

[8] D. B. Reiff and J. Dow, "Case report: invasive renal angiomyolipoma-sonographic and CT features," Clinical Radiology, vol. 48, no. 4, pp. 283-285, 1993.

[9] N. Honda, K. Matsuoka, K. Fujimoto et al., "Renal angiomyolipoma extending into inferior vena cava: MR demonstration," Journal of Computer Assisted Tomography, vol. 17, no. 1, pp. 161$162,1993$.

[10] S. B. Morris, S. J. Hampson, P. Jackson, T. Treasure, and R. J. Shearer, "Surgical management of an angiomyolipoma extending into the inferior vena cava," British Journal of Urology, vol. 74, no. 3, pp. 383-385, 1994.

[11] G. Moulin, J.-F. Berger, C. Chagnaud, P. Piquet, and J.-M. Bartoli, "Imaging of fat thrombus in the inferior vena cava originating from an angiomyolipoma," CardioVascular and Interventional Radiology, vol. 17, no. 3, pp. 152-154, 1994.

[12] R. A. Leder, "Genitourinary case of the day. Angiomyolipoma of the kidney with fat thrombus in the inferior vena cava," American Journal of Roentgenology, vol. 165, no. 1, pp. 198-199, 1995.

[13] H. Hibi, M. Takashi, Y. Yamada, M. Yamamoto, and T. Shimoji, "Angiomyolipoma of the kidney with extension into the inferior vena cava," International Journal of Urology, vol. 2, no. 5, pp. 332-335, 1995.

[14] J. Baert, B. Vandamme, R. Sciot, R. Oyen, H. van Poppel, and L. Baert, "Benign angiomyolipoma involving the renal vein and vena cava as a tumor thrombus: case report," Journal of Urology, vol. 153, no. 4, pp. 1205-1207, 1995.

[15] G. Cittadini Jr., F. P. Mucelli, F. M. Danza, L. E. Derchi, and R. S. P. Mucelli, “Aggressive' renal angiomyolipoma," Acta Radiologica, vol. 37, no. 6, pp. 927-932, 1996.

[16] J. Rubio-Briones, J. P. Redorta, J. S. Bayarri et al., "Incidentally detected renal angiomyolipoma with tumour thrombus into the inferior vena cava," Scandinavian Journal of Urology and Nephrology, vol. 31, no. 2, pp. 189-191, 1997.

[17] M. R. Bernstein, S. B. Malkowicz, E. S. Siegelman, M. Acker, J. E. Tomaszewski, and A. J. Wein, "Progressive angiomyolipoma with inferior vena cava tumor thrombus," Urology, vol. 50, no. 6, pp. 975-977, 1997.

[18] A. Gotoh, K. Gohji, M. Fujisawa et al., "Renal angiomyolipoma associated with inferior vena caval tumour thrombus," British Journal of Urology, vol. 81, no. 5, pp. 773-774, 1998.

[19] A. P. Christiano, X. Yang, and G. S. Gerber, "Malignant transformation of renal angiomyolipoma," Journal of Urology, vol. 161, no. 6, pp. 1900-1901, 1999. 
[20] H. Ito, S. Nakashima, H. Toma, and T. Misaki, "Renal angiomyolipoma associated with inferior vena caval and right atrial thrombus," Journal of Urology, vol. 162, no. 4, pp. 1371-1372, 1999.

[21] M. I. Davydov, V. B. Matveev, A. B. Lukianchenko, B. V. Kudashev, and N. N. Petrovichev, "Renal angiomyolipoma extending into the right atrium," Urologia Internationalis, vol. 67, no. 2, pp. 168-169, 2001.

[22] S. S. Wilson, P. E. Clark, and J. P. Stein, "Angiomyolipoma with vena caval extension,” Urology, vol. 60, no. 4, pp. 695-696, 2002.

[23] L. Schips, M. Ratschek, G. Gallé et al., "Angiomyolipoma with a caval thrombus," Urologia Internationalis, vol. 70, no. 4, pp. 332-334, 2003

[24] X. Gamé, M. Soulié, S. Moussouni et al., "Renal angiomyolipoma associated with rapid enlargment and inferior vena caval tumor thrombus," Journal of Urology, vol. 170, no. 3, pp. 918-919, 2003.

[25] A. H. M. M. Islam, T. Ehara, H. Kato, M. Hayama, T. Kashiwabara, and O. Nishizawa, "Angiomyolipoma of kidney involving the inferior vena cava," International Journal of Urology, vol. 11, no. 10, pp. 897-902, 2004.

[26] T. Haritharan, S. Sritharan, and S. Bhimji, "Renal angiomyolipoma with inferior vena caval involvement," Medical Journal of Malaysia, vol. 61, no. 4, pp. 493-495, 2006.

[27] Y. Akcali, O. I. Karahan, G. Kahriman, H. Ceyran, and S. Balkanli, "Angiomyolipoma with cavoatrial extension," European Urology, vol. 50, no. 3, pp. 605-606, 2006.

[28] H. K. Park, S. Zhang, M. K. K. Wong, and H. L. Kim, "Clinical presentation of epithelioid angiomyolipoma," International Journal of Urology, vol. 14, no. 1, pp. 21-25, 2007.

[29] G. R. Schade, O. N. Gofrit, and K. C. Zorn, "Renal angiomyolipoma with intravascular extension into the inferior vena cava: a case report and review of the literature," The Canadian Journal of Urology, vol. 15, no. 2, pp. 4012-4015, 2008.

[30] D. Ban, S. Yamamoto, H. Kuno et al., "A case of huge colon carcinoma and right renal angiomyolipoma accompanied by proximal deep venous thrombosis, pulmonary embolism and tumor thrombus in the renal vein," Japanese Journal of Clinical Oncology, vol. 38, no. 10, pp. 710-714, 2008.

[31] S. M. Moudouni, M. Tligui, M. Sibony et al., "Malignant epithelioid renal angiomyolipoma involving the inferior vena cava in a patient with tuberous sclerosis," Urologia Internationalis, vol. 80, no. 1, pp. 102-104, 2008.

[32] M. W. Christian and T. D. Moon, "Renal angiomyolipoma with inferior vena caval thrombus in a 32-year-old male," Indian Journal of Urology, vol. 25, no. 4, pp. 529-530, 2009.

[33] X. Durand, R. Renard-Penna, E. Comperat, M. O. Bitker, and F. Richard, "Renal angiomyolipoma associated with inferior vena cava thrombus," Case Reports in Medicine, vol. 2009, Article ID 789078, 3 pages, 2009.

[34] Y. S. Tan, K. H. Yip, P. H. Tan, and W. S. Cheng, "A right renal angiomyolipoma with IVC thrombus and pulmonary embolism," International Urology and Nephrology, vol. 42, no. 2, pp. 305-308, 2010.

[35] C. Govednik-Horny and M. Atkins, "Angiomyolipoma with vascular invasion during pregnancy," Annals of Vascular Surgery, vol. 25, no. 8, pp. 1138.e9-1138.e13, 2011.

[36] J. Lopater, O. Hartung, F. Bretelle, and C. Bastide, "Management of angiomyolipoma vena cava thrombus during pregnancy," Obstetrics and Gynecology, vol. 117, no. 2, pp. 440-443, 2011.

[37] V. Mittal, B. S. Aulakh, and G. Daga, "Benign renal angiomyolipoma with inferior vena cava thrombosis," Urology, vol. 77, no. 6, pp. 1503-1506, 2011.
[38] C. Grant, J. M. Lacy, and S. E. Strup, "A 22-year-old female with invasive epithelioid angiomyolipoma and tumor thrombus into the inferior vena cava: case report and literature review," Case Reports in Urology, vol. 2013, Article ID 730369, 3 pages, 2013.

[39] X. Li, Q. Li, Y. Miao et al., "A case of renal angiomyolipoma with intracardiac extension and asymptomatic pulmonary embolism," International Journal of Clinical and Experimental Pathology, vol. 6, no. 6, pp. 1180-1186, 2013.

[40] H.-M. Li, L.-R. Yeh, and K. Lu, "Renal angiomyolipoma with coexistent hemorrhagic aneurysm formation and fatty thrombus in inferior vena cava: a rare presentation," Abdominal Imaging, vol. 38, no. 1, pp. 180-183, 2013.

[41] S. Fernandez-Pello, I. G. Rodriguez, L. R. Villamil et al., "Laparoscopic management of right renal angiomyolipoma with involvement of the inferior vena cava: case report and review of the literature," Scandinavian Journal of Urology, vol. 47, no. 4, pp. 340-344, 2013.

[42] Y. Nouira, Y. Kallel, M. Gargouri et al., "Renal angiomyolipoma with Fatty thrombus extending to the right atrium: an exceptional presentation," Case Reports in Urology, vol. 2013, Article ID 120383, 3 pages, 2013.

[43] C. K. Sandstrom, J. Pugsley, and L. M. Mitsumori, "Renal angiomyolipoma with nontraumatic pulmonary fat embolus," American Journal of Roentgenology, vol. 192, no. 6, pp. W275W276, 2009.

[44] H. P. H. Neumann, G. Schwarzkopf, and E. P. Henske, "Renal angiomyolipomas, cysts, and cancer in tuberous sclerosis complex," Seminars in Pediatric Neurology, vol. 5, no. 4, pp. 269-275, 1998.

[45] N. Nese, G. Martignoni, C. D. Fletcher et al., "Pure epithelioid PEComas (so-called epithelioid angiomyolipoma) of the kidney: a clinicopathologic study of 41 cases: detailed assessment of morphology and risk stratification," American Journal of Surgical Pathology, vol. 35, no. 2, pp. 161-176, 2011.

[46] J. N. Eble, M. B. Amin, and R. H. Young, "Epithelioid angiomyolipoma of the kidney: a report of five cases with a prominent and diagnostically confusing epithelioid smooth muscle component," American Journal of Surgical Pathology, vol. 21, no. 10, pp. 1123-1130, 1997.

[47] M. Pea, F. Bonetti, G. Martignoni et al., "Apparent renal cell carcinomas in tuberous sclerosis are heterogeneous: the identification of malignant epithelioid angiomyolipoma," American Journal of Surgical Pathology, vol. 22, no. 2, pp. 180-187, 1998.

[48] E. Wyluda, G. Baquero, N. Lamparella, C. Abendroth, and J. Drabick, "Fatal malignant metastastic epithelioid angiomyolipoma presenting in a young woman: case report and review of the literature," Rare Tumors, vol. 5, no. 3, article e46, 2013.

[49] O. Hélénon, S. Merran, F. Paraf et al., "Unusual fat-containing tumors of the kidney: a diagnostic dilemma," Radiographics, vol. 17, no. 1, pp. 129-144, 1997.

[50] M. Jinzaki, A. Tanimoto, Y. Narimatsu et al., "Angiomyolipoma: imaging findings in lesions with minimal fat," Radiology, vol. 205, no. 2, pp. 497-502, 1997.

[51] M. S. Steiner, S. M. Goldman, E. K. Fishman, and F. F. Marshall, "The natural history of renal angiomyolipoma," Journal of Urology, vol. 150, no. 6, pp. 1782-1786, 1993.

[52] C. P. Nelson and M. G. Sanda, "Contemporary diagnosis and management of renal angiomyolipoma," Journal of Urology, vol. 168, no. 4, pp. 1315-1325, 2002.

[53] S. Fazeli-Matin and A. C. Novick, "Nephron-sparing surgery for renal angiomyolipoma," Urology, vol. 52, no. 4, pp. 577-583, 1998. 
[54] S. A. Boorjian, I. Frank, B. Inman et al., "The role of partial nephrectomy for the management of sporadic renal angiomyolipoma," Urology, vol. 70, no. 6, pp. 1064-1068, 2007.

[55] A. Minervini, G. Giubilei, L. Masieri, F. Lanzi, S. Serni, and M. Carini, "Simple enucleation for the treatment of renal angiomyolipoma," BJU International, vol. 99, no. 4, pp. 887-891, 2007.

[56] T. Harabayashi, N. Shinohara, H. Katano, K. Nonomura, T. Shimizu, and T. Koyanagi, "Management of renal angiomyolipomas associated with tuberous sclerosis complex," Journal of Urology, vol. 171, no. 1, pp. 102-105, 2004.

[57] N. Shinohara, M. Kotegawa, Y. Kiyohara et al., "An autopsy case of pulmonary embolism due to renal angiomyolipoma in an elderly woman," Nippon Ronen Igakkai Zasshi, vol. 36, no. 6, pp. 420-424, 1999.

[58] E. H. Kim, S. Jain, B. M. Benway, and R. S. Figenshau, "Partial nephrectomy in two patients with known T3a tumours involving the renal vein," BJU International, vol. 109, no. 9, pp. 1345-1348, 2012.

[59] S. B. Kolla, C. Ercole, P. E. Spiess, J. M. Pow-Sang, and W. J. Sexton, "Nephron-sparing surgery for pathological stage T3b renal cell carcinoma confined to the renal vein," BJU International, vol. 106, no. 10, pp. 1494-1498, 2010.

[60] S. L. Woldu, L. J. Barlow, T. Patel, G. W. Hruby, M. C. Benson, and J. M. McKiernan, "Single institutional experience with nephron-sparing surgery for pathologic stage T3bNxM0 renal cell carcinoma confined to the renal vein," Urology, vol. 76, no. 3, pp. 639-642, 2010. 


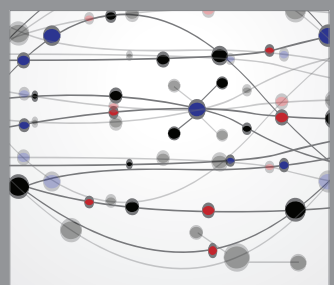

The Scientific World Journal
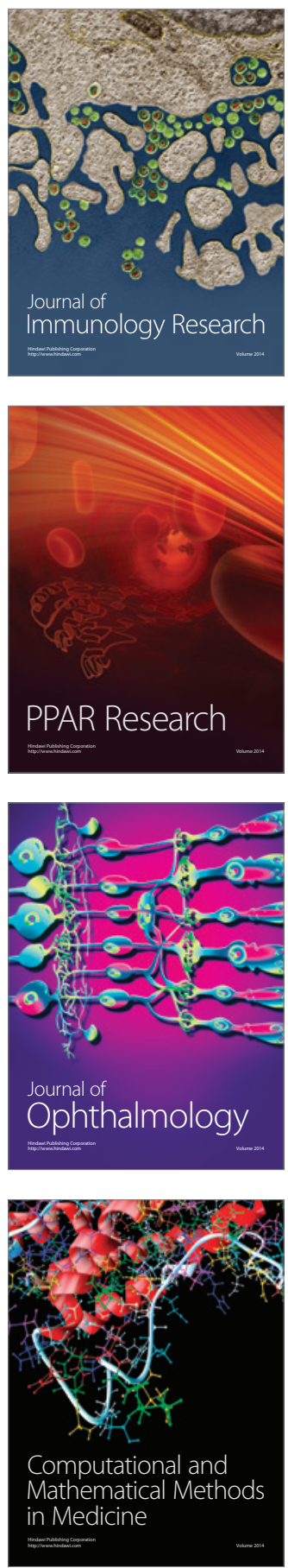

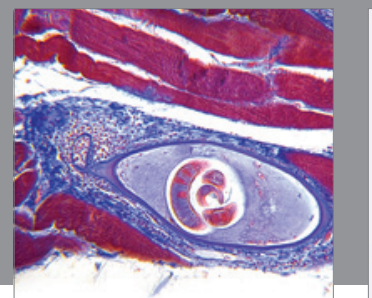

Gastroenterology

Research and Practice
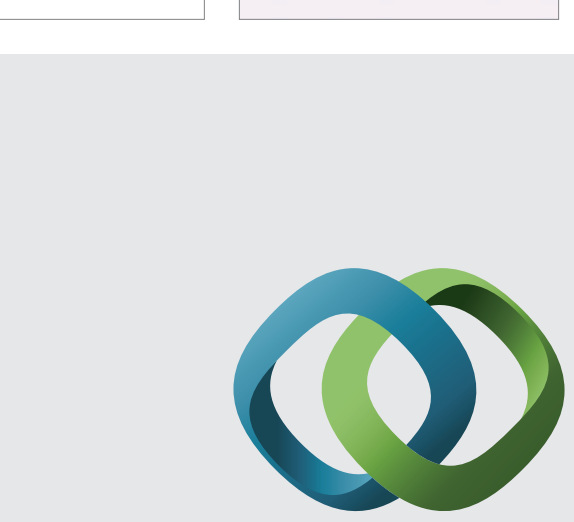

\section{Hindawi}

Submit your manuscripts at

http://www.hindawi.com
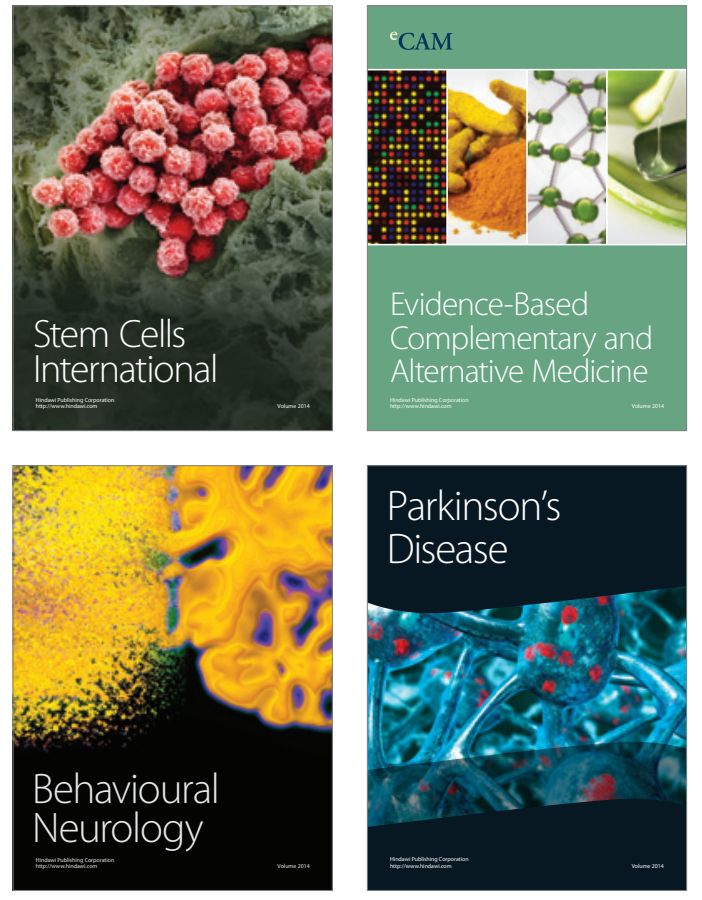
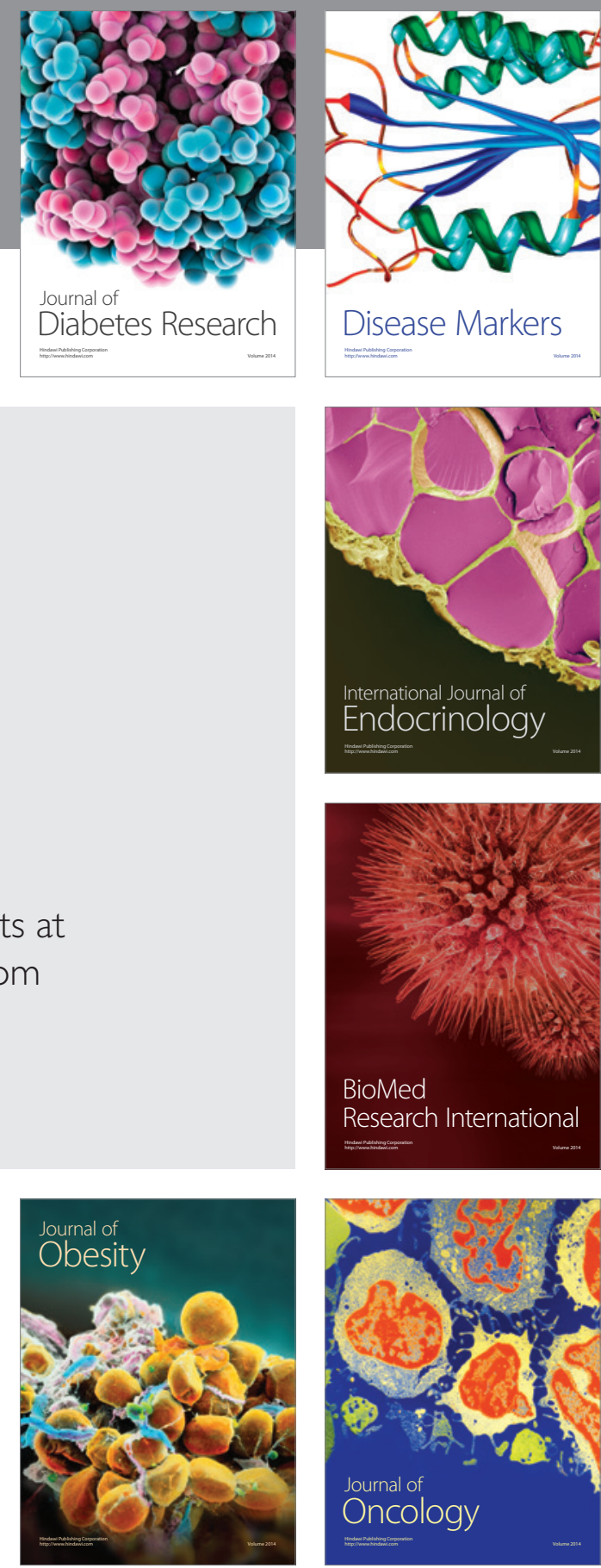

Disease Markers
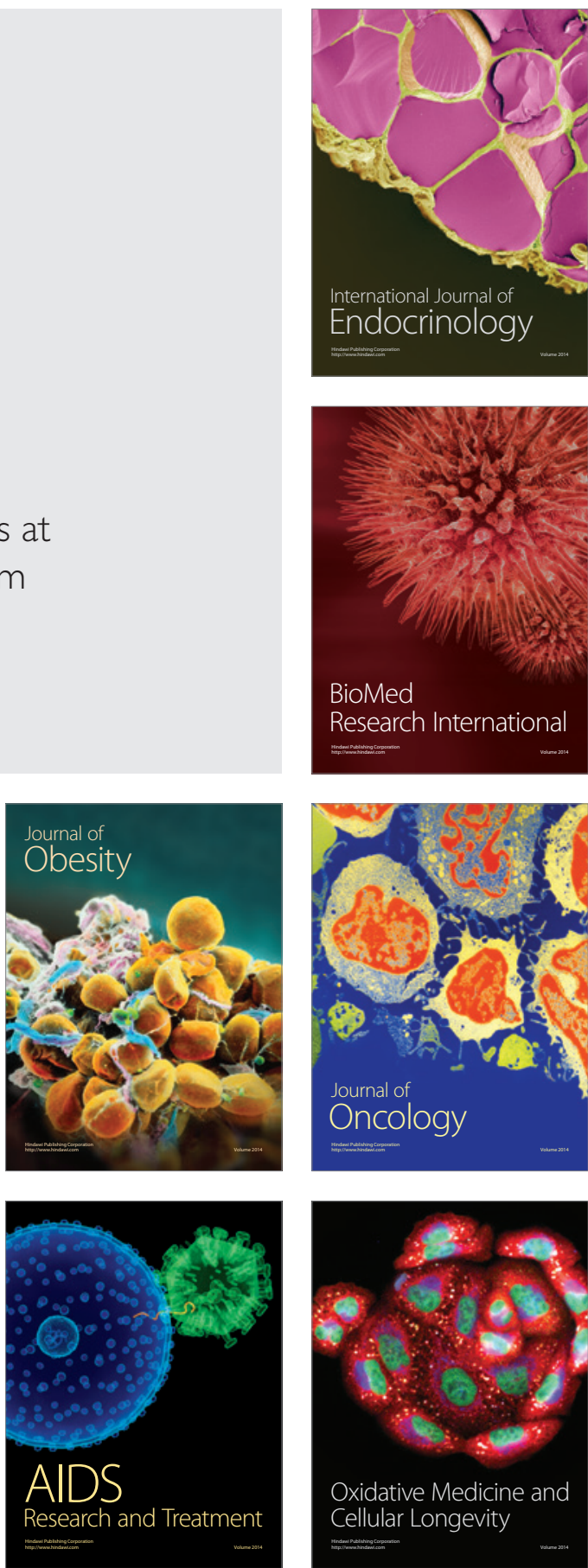